\title{
Reversible Schamroth Sign after Pleural Tumor Resection
}

\author{
Simon Bossart Anna Rammlmair Eckart Haneke \\ Department of Dermatology, Inselspital, University Hospital of Bern, Bern, Switzerland
}

\section{Established Facts}

- The Schamroth sign is a clinical sign associated with nail clubbing.

- The most common causes of nail clubbing are pulmonary and cardiovascular diseases.

\section{Novel Insights}

- New nail clubbing with positive Schamroth sign may indicate a neoplastic pulmonary disease.

- A Schamroth sign can be reversible after pulmonary tumor resection.

\section{Keywords}

Schamroth sign · Nail clubbing · Digital acropachy

\section{Abstract}

The Schamroth sign can be used for the detection of nail clubbing and is associated with pulmonary and cardiovascular diseases. This case illustrates a patient with sudden nail clubbing and positive Schamroth sign without any other abnormal clinical or laboratory findings. Radiological workup revealed a pleural tumor, histologically confirmed as a solitary fibrous tumor. After thoracoscopic tumor resection, normalization of the nail clubbing with complete resolution of the Schamroth sign was observed. Our case demonstrates that sudden nail changes with positive Schamroth sign may indicate a new neoplastic pulmonary disease. It is of great importance to increase the awareness of this feature in order to obtain a timely diagnosis, specific treatment, and improved patient care.

(c) 2019 S. Karger AG, Basel

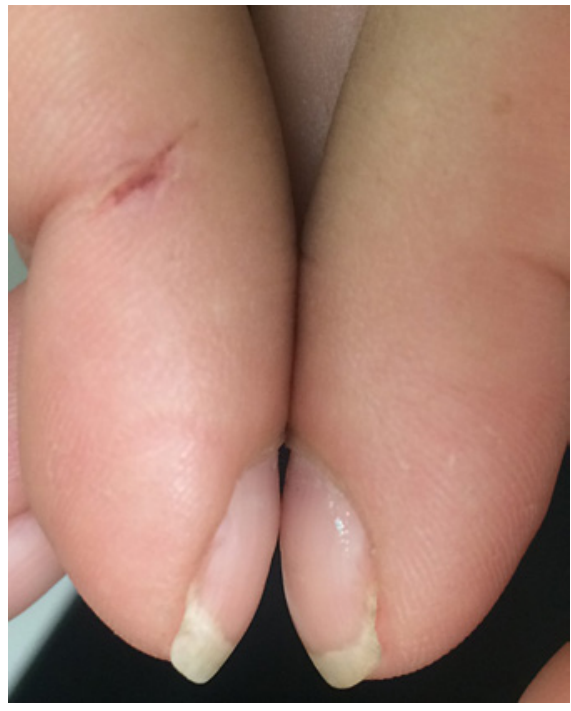

Fig. 1. Positive Schamroth sign between both thumbs.

\section{KARGER}

(C) 2019 S. Karger AG, Basel

E-Mail karger@karger.com

www.karger.com/sad
Simon Bossart, MD

Department of Dermatology

Inselspital, University Hospital of Bern

$\mathrm{CH}-3010$ Bern (Switzerland)

E-Mail simon.bossart@insel.ch 


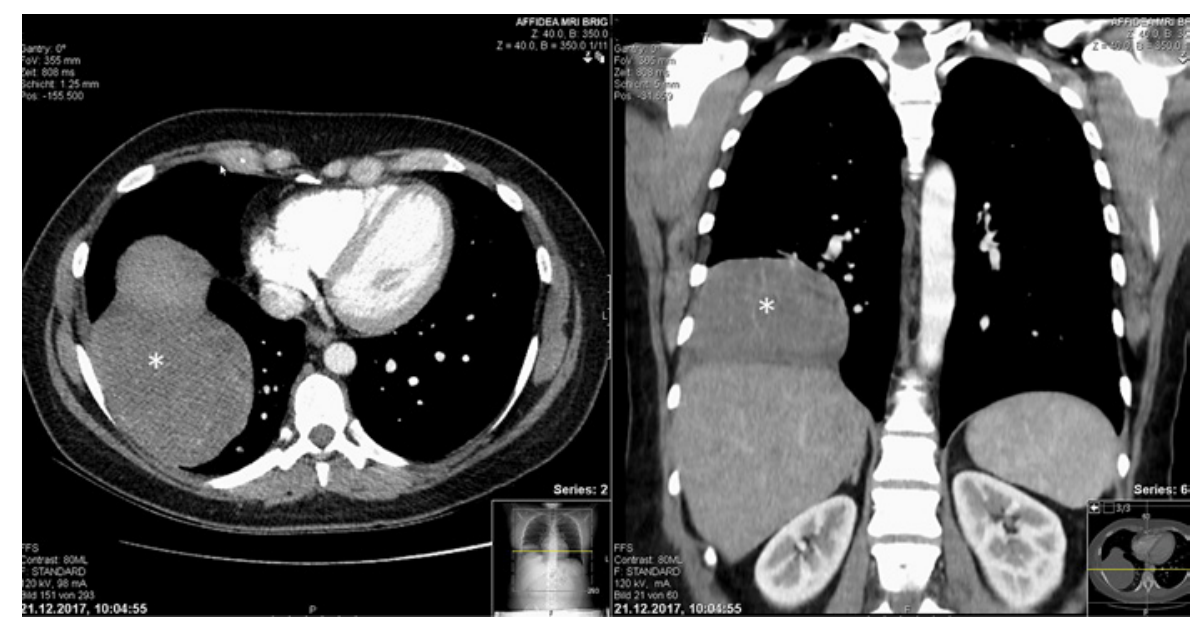

Fig. 2. CT scan with pleural tumor in the right lower lobe $\left(^{*}\right)$.

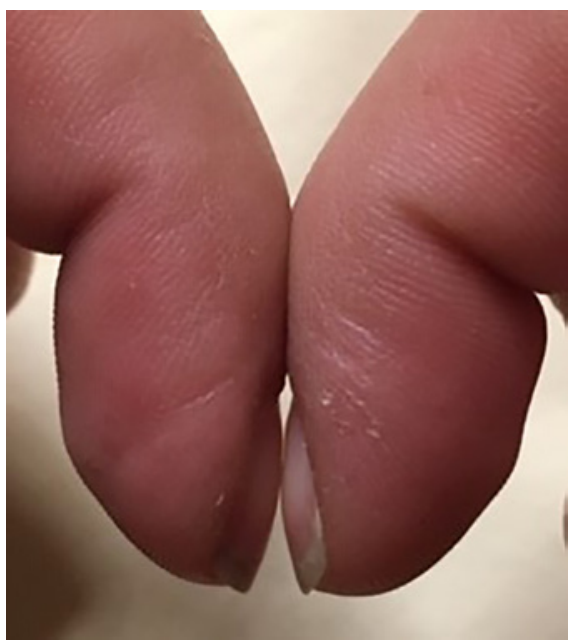

Fig. 3. Negative Schamroth sign between both thumbs 5 months after tumor resection.

\section{Case Report}

Four months ago, a 40-year-old, otherwise healthy female presented with suddenly increasing longitudinal curvature of her fingernails. Physical examination revealed nail clubbing with curved nails and a slight digital acropachy on both hands. The Schamroth sign between the thumbs was positive (no diamond-shaped aperture between the fingers; Fig. 1). Laboratory parameters for thyroid function and systemic inflammation were normal. In order to exclude an underlying pulmonary disorder, a chest radiograph was taken, showing a tumor in the right lower lobe. This pleural tumor was confirmed by computed tomography (CT) (Fig. 2). A thoracoscopic resection of the tumor was performed. Histopathology revealed a solitary fibrous tumor. Five months after tumor resection, there was normalization of all fingernails with a negative Schamroth sign between the thumbs (Fig. 3).

\section{Discussion/Conclusion}

First described in 1976, Schamroth reported a clinical sign associated with nail clubbing, where normally a diamond-shaped aperture appears by opposing any distal finger phalanges [1]. In a patient with nail clubbing, this aperture is obliterated. The Schamroth sign has been studied as a valid measure of clubbing and was found to have high interrater reliability [2]. Another measure of clubbing is the angle between nail plate and proximal fold. It is normally $<160^{\circ}$. In clubbing, this angle is increased to $>180^{\circ}$ due to the curvature of the nail (Lovibond's angle) [3].

Nail clubbing can be hereditary, but more often it is a sign of pulmonary or cardiovascular disease. The underlying pathogenesis is unknown. It may be the result of

connective tissue proliferation between the nail matrix and the distal phalanx [4].

To date, there is only 1 reported case of a reversible Schamroth sign in a patient with nonspecific interstitial pneumonia successfully treated with oral steroids [5].

The present case illustrates that sudden nail changes with nail clubbing and positive Schamroth sign may indicate a neoplastic pulmonary disease. Timely recognition of this feature is crucial in order to obtain rapid diagnosis, specific treatment, and improved patient care.

\section{Statement of Ethics} report.

The patient was informed and gave her consent to publish the

\section{Disclosure Statement}

The authors have no conflicts of interest to declare.

References

Skin Appendage Disord 2019;5:327-328 DOI: $10.1159 / 000497463$
1 Schamroth L. Personal experience. S Afr Med J. 1976 Feb;50(9):297-300.

2 Pallarés-Sanmartín A, Leiro-Fernández V, Cebreiro TL, Botana-Rial M, Fernández-Villar A. Validity and reliability of the Schamroth sign for the diagnosis of clubbing. JAMA. 2010 Jul;304(2):159-61.

3 Motswaledi M, Mayayise M. Nail changes in systemic diseases. S Afr Fam Pract. 2010; 52(5):409-13.

4 Karnath B. Digital clubbing: A sign of underlying disease. Hosp Physician. 2003;26:25-7.

5 Maiso A, Dominguez-Juncal L, Marcos PJ. Reversible Schamroth sign. Arch Bronconeumol. 2016 Mar;52(3):167. 